\title{
The role of ethanol in the pathogenesis of non-bacterial prostatitis
}

\author{
FENG LIU ${ }^{1}$, LINTAO LIU ${ }^{1}$, ZHONG WANG $^{1}$, LIN CHEN $^{1}$, JIANJUN YU $^{1,2}$ and XIAOLIN XU ${ }^{1}$ \\ ${ }^{1}$ Department of Urology, Shanghai Fengxian District Central Hospital, Shanghai 201499; ${ }^{2}$ Department of Urology, \\ Shanghai Jiaotong University Affiliated The Sixth People's Hospital, Shanghai 200233, P.R. China
}

Received December 7, 2017; Accepted September 4, 2018

DOI: $10.3892 / \mathrm{mmr} .2019 .9991$

\begin{abstract}
Chronic prostatitis (CP) is a common disease within the field of urology, and it is difficult to treat. Prostatitis mainly occurs in young men and presents with various clinical symptoms, manifested as urinary frequency, urinary urgency, urinary pain, prolonged urination, dysuria and other urinary abnormalities. There are various forms of the syndrome that can cause discomfort or pain in the perineum, the lower abdomen, the penis, the scrotum and the lumbosacral area. To investigate $\mathrm{CP}$ in more detail, animal models are necessary to determine the etiology of prostatitis and develop new, specific drug therapies. In the present study, Sprague Dawley rats that were induced to develop a model of chronic and non-bacterial prostatitis drank ethanol or water to determine the effects of ethanol on prostatitis. Total antioxidant capacity, the concentration of inflammatory factors, such as tumor necrosis factor- $\alpha$ and interleukin-1 $\beta$, and the expression changes of $\alpha 1$-adrenoreceptor were measured. The susceptibility of ethanol-drinking rats to $\mathrm{CP}$ was confirmed and some simple mechanism of this susceptibility was investigated to further guide the diagnosis and treatment of patients with prostatitis.
\end{abstract}

\section{Introduction}

With the rapid development of social economies, standards are increasing and drinking alcohol has become a common social activity (1). In this a social environment, drinking behavior is continuously increasing, and if an individual drinker suffers from a psychopathological condition, drinking can easily develop into alcohol abuse and dependence. Alcohol consumption has resulted in a series of far-reaching social and medical issues (2). Diseases caused by alcohol abuse are attracting increasing attention from the medical community $(3,4)$. Alcohol-associated diseases are often reported, and alcoholism is associated serious systemic system damage and causes social dysfunction and mental health disorders, resulting in a series of social and medical problems $(5,6)$.

Correspondence to: Professor Xiaolin Xu, Department of Urology, Shanghai Fengxian District Central Hospital, 6600 Nanfeng Road, Shanghai 201499, P.R. China

E-mail: 30689067@qq.com

Key words: chronic prostatitis, inflammatory factors, ethanol
Chronic prostatitis (CP) is a common urological disease in men. Patients typically present with pain in the lower abdomen, perineum, scrotum, penis, lumbosacral area and other areas of discomfort (7). Numerous patients also experience different degrees of sexual dysfunction, neuropsychiatric symptoms, fatigue and insomnia. Although CP does not cause a significant threat to life, it can seriously affect the quality of life of patients, particularly for patients with mental health issues $(8,9)$. However, the pathogenesis and pathophysiological changes that cause CP remain unclear $(10,11)$. Currently, there are no effective drugs or methods to treat the disease, and it is imperative to identify safe and cost-effective treatments. A previous study reported that $\mathrm{CP}$ may be caused by changes in hormone secretion levels and immunological dysfunction (12).

Drinking is a habit closely associated with male patients. Moderate drinking is able to promote blood circulation to improve the function of the human body but a high degree of drinking can affect human health. Alcohol can also increase the severity of prostate congestion. In addition to the direct effects of alcohol on the nervous system, the prostate is also very sensitive to alcohol, and it is prone to prostate disease (13). Currently, there is limited research on the effect of alcohol on prostatitis.

In the present study, it was attempted to investigate the association of ethanol consumption and $\mathrm{CP}$, where rats with $\mathrm{CP}$ were treated with or without ethanol, to explore the mechanism and role of alcohol CP (14). A chronic non-bacterial prostatitis model was successfully established in rats. In conclusion, ethanol increased the inflammatory responses in the prostate of rats with non-bacterial prostatitis.

\section{Materials and methods}

Animals. Healthy male Sprague Dawley (SD) rats $(n=24$; age, 6-7 weeks; weight, 180-200 g), were purchased from the Animal Experimental Center of Shanghai Jiaotong University (Shanghai, China). Animal room temperature control was at $25^{\circ} \mathrm{C}$, humidity control was at $60 \%$, and 12 -h light cycle was used to simulate the normal circadian physiology. Drinking water and standard food were available to animals following sterilization. The establishment of non-bacterial prostatitis model was performed as reported in a previous study (15). The rats were injected intraperitoneally with $3 \mathrm{mg} / \mathrm{ml}$ complete Freund's adjuvant, $1 \mathrm{mg}$ purified prostaglandin and $0.1 \mathrm{ml}$ DPT vaccine to induce non-bacterial prostatitis in rats $(16,17)$. The Bioethics Committee of Shanghai Jiaotong University approved all animal 
experiments, which were performed in accordance with the National Institutes of Health Guide for the Care and Use of Laboratory Animals (https:/grants.nih.gov/grants/olaw/guidefor-the-care-and-use-of-laboratory-animals.pdf), the Ethical Certificate number was SYXK (Shanghai) 2011-0128. Rats were divided into four groups (6 rats/group): A (normal SD rats), $\mathrm{B}$ (ethanol-drinking rats), $\mathrm{C}$ (chronic non-bacterial prostatitis rats) and D (ethanol-drinking chronic non-bacterial prostatitis rats).

Blood tests. Blood was collected from heart by cardiocentesis. The white blood cells (WBC), and concentrations of $\mathrm{IgG}$, serum testosterone (serum T) and dihydrotestosterone (DHT) were analyzed by Animal blood routine detector (Acon, Shanghai, China).

Preparation of rat prostate protein purification solution. A total of $10 \mathrm{SD}$ rats were sacrificed, the body weight of each rat having been recorded. Following disinfection and dissection, the prostate was exposed, removed and put into iced saline. The weight of the prostate was recorded. The prostate index was the weight of prostate/body weight. The tissue was cleansed and diced, followed by homogenization. Samples were centrifuged for $30 \mathrm{~min}(20,000 \mathrm{x} \mathrm{g})$ at $4^{\circ} \mathrm{C}$. A suction tube was used to remove the upper adipose tissue, and then $3 \mathrm{ml}$ supernatant was placed in cryopreservation storage. Bicinchoninic protein assay was used for protein concentration quantification (Beyotime Institute of Biotechnology, Haimen, China) and the protein was diluted to a concentration of $50 \mathrm{mg} / \mathrm{ml}(18)$.

Hematoxylin and eosin $(H \& E)$ staining. After the rats were sacrificed, a sample of prostate was fixed in $4 \%$ formalin for $24 \mathrm{~h}$ then placed in $70-100 \%$ graded ethanol series the subsequent day. The prostate was embedded in paraffin followed by dehydration and was sectioned at $4 \mu \mathrm{m}$ of thickness. The prostate sections were deparaffinized and rehydrated (100-70\%), then stained with hematoxylin (15 min) and eosin (2 min) at room temperature, and observed under an inverted microscope (Nikon TS-100-F; Nikon Corporation, Tokyo, Japan) (19).

Measurement of inflammatory factors. The prostate tissue of each group was immersed in a physiological saline solution containing $0.5 \%$ Triton $\mathrm{X}-100$ and homogenized in a glass homogenizer on an ice-water bath. The prostate tissue was equilibrated into $10 \%$ prostate tissue homogenate and centrifuged at $300 \mathrm{x} \mathrm{g}$ for $15 \mathrm{~min}$ at $4^{\circ} \mathrm{C}$. The supernatant was collected according to the ELISA kit instructions to measure tumor necrosis factor (TNF)- $\alpha$ (catalog number ab46070; Abcam, Cambridge, UK), inducible nitric oxide synthase (iNOS) (catalog number: MBS263618; MyBioSource, Inc., San Diego, CA, USA) and total antioxidant capacity (T-AOC) kit (catalog number STA-360; Cell Biolabs, Inc., San Diego, CA, USA).

Evaluation of prostatic inflammation. Inflammatory scores (20) were given to the prostatic tissue of rats in each group. The standard of evaluation was the ratio of the area of the lesion to the total area (5 visual fields were randomly selected from each slice). No lesion present was denoted as $0,25 \%$ was denoted

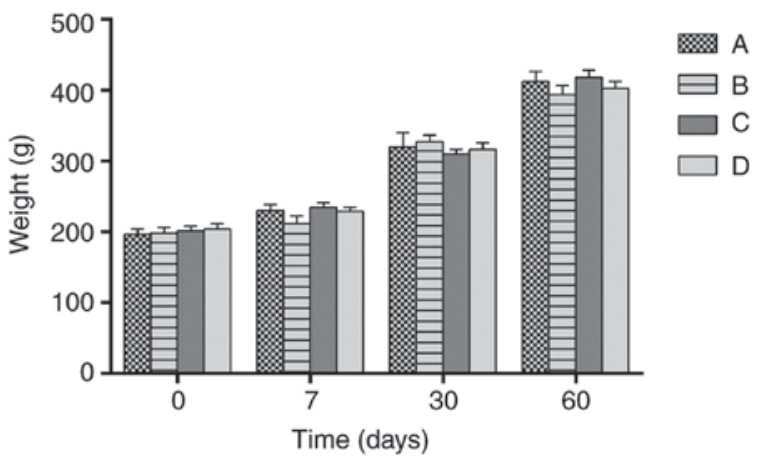

Figure 1. Body weight of group A (normal rats), group B (ethanol-drinking rats), group $\mathrm{C}$ (chronic non-bacterial prostatitis rats) and group D (ethanol-drinking chronic non-bacterial prostatitis rats) at different time-points. No significant differences were observed among groups at each time-point.

as 1 point, $50 \%$ was denoted as 2 points, $75 \%$ was denoted as 3 points and $100 \%$ was denoted as 4 points (21).

Reverse transcription-quantitative polymerase chain reaction $(R T-q P C R)$. RT-qPCR was performed as previously described (9), followed by the use of SYBR Premix Ex Taq II kit (catalog number RR82LR; Takara Bio, Inc., Otsu, Japan). mRNA was extracted from the prostate tissue of rats using TRIzol (Invitrogen; Thermo Fisher Scientific, Inc., Waltham, MA, USA). PCR was performed with the following thermocycling conditions: $5 \mathrm{~min}$ at $95^{\circ} \mathrm{C}$, followed by 40 cycles of $95^{\circ} \mathrm{C}$ for $30 \mathrm{sec}, 55^{\circ} \mathrm{C}$ for $30 \mathrm{sec}$ and $72^{\circ} \mathrm{C}$ for $30 \mathrm{sec}$, with a final holding step at $4 \mathrm{C}$. The thermocycler used in the present study was the StepOnePlus ${ }^{\mathrm{TM}}$ Real-Time PCR system (Applied Biosystems; Thermo Fisher Scientific, Inc.). The primers were obtained from Funengbio Co. (Shanghai, China). Primers sequences were as follows: $\alpha$ la-adrenoreceptor (AR), forward, TAGCCTFTCACCGACACCTG and reverse, GGAGGT CGGCCACCG; $\alpha 1 b-A R$, forward, CTCAACCCCATCATC TACCCA and reverse, CTCAACCCCATCATCTACCCA; ald-AR, forward, AGCGCTTCTGCGGTATCA and reverse, CAGGTAGAAGGAGCACACGG; GAPDH, forward, TCT AGACGGCAGGTCAGGTCCAC and reverse, CCACCCATG GCAAATTCCATGGCA. RT-qPCR was performed using an Applied Biosystems 7500 real-time PCR system (Applied Biosystems; Thermo Fisher Scientific, Inc.). The results were analyzed using Light Cycler Software version 3.5 (Idaho Technology Inc., Salt Lake City, UT, USA). The $2^{-\Delta \Delta C q}$ method was performed to calculate the relative expression (22).

Statistical analysis. The data are presented as the mean \pm standard deviation and analyzed using GraphPad prim 6.0 (GraphPad Software, Inc., La Jolla, CA, USA). The statistical significance was determined by one-way analysis of variance followed by the least significant difference post hoc test. $\mathrm{P}<0.05$ was considered to indicate a statistically significant difference.

\section{Results}

Body weight in each group of SD rats. As shown in Fig. 1, there were no significant differences in body weight among the groups. 

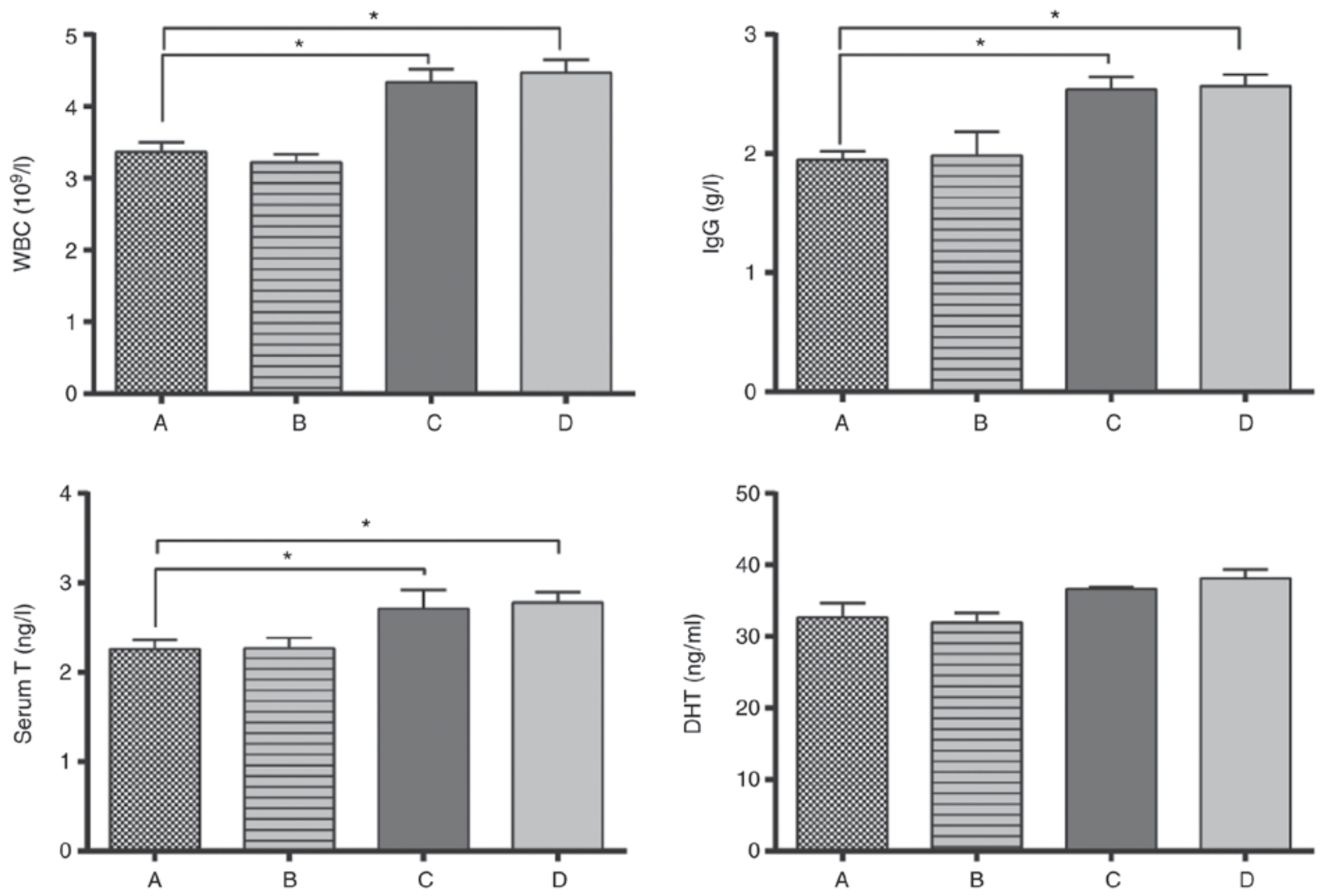

Figure 2. Blood parameters in group A (normal rats), group B (ethanol-drinking rats), group C (chronic non-bacterial prostatitis rats) and group D (ethanol-drinking chronic non-bacterial prostatitis rats). "P $<0.05$. WBC, white blood cells; IgG, immunoglobulin G; serum T, serum testosterone; DHT, dihydrotestosterone.

Blood tests were performed on all rats. Compared with the normal control group A, there was no significant difference in the blood parameters of group B ( $\mathrm{P}>0.05 ;$ Fig. 2$)$.

There were significant differences in blood parameters between groups $C, D$ and $A, B$. The total count of white blood cells (WBC), and concentrations of IgG, serum testosterone (serum T) in group $\mathrm{C}$ and Group D were higher compared with Group A and Group B $(\mathrm{P}<0.05)$. No difference in the expression of DHT, important for development and maintenance of the prostate gland and seminal vesicles, was observed among the 4 groups.

Prostate morphology in each group of rats. There was no difference in the morphology of the prostate between groups A and B. The surface of the organ was smooth, the capsules were intact without edema, there were no glandular congestions and prostatic fluids were clear (Fig. 3A and B). In groups $\mathrm{C}$ and $\mathrm{D}$, prostates exhibited edema and adhesions, had enlarged volume and local congestion of glands. The congestion and volume of the prostate in group $\mathrm{D}$ was higher than in group C (Fig. 3C and D).

Pathological examination of the prostate. $\mathrm{H} \& \mathrm{E}$ staining indicated that the cells in groups A and B sections were neatly arranged, with no obvious infiltration of inflammatory cells. The epithelial cells were arranged in rows as either cubic or columnar epithelium (Fig. 4A and B). In group C, there was hyperplasia of the prostate epithelium, infiltration of interstitial inflammatory cells, and a certain degree of interstitial edema and enlargement. Group D exhibited infiltration of inflammatory cells, while the expansion of the prostate capsule and interstitial blood vessels was marked and accompanied by glandular injury (Fig. 4C and D).

Wet weight and index of the prostate. There were no significant differences in prostate wet weight and prostate index among the groups (Fig. 5).

Evaluation of prostatic inflammation. Inflammatory scores (20) were given to the prostatic tissue of rats in each group (Fig. 6). The results demonstrated that there was no significant difference in inflammation between groups A and B. The inflammation scores of groups $\mathrm{C}$ and $\mathrm{D}$ were significantly higher than those of group A, and the inflammation scores of group D were significantly higher than that of group C.

Expression of inflammatory factors in prostate. The expression of TNF- $\alpha$ and iNOS in groups C and D were significantly higher than those in groups A and B. The T-AOC levels in groups $\mathrm{C}$ and $\mathrm{D}$ was significantly lower than that in group $\mathrm{A}$, while the expression of T-AOC in group D was significantly lower than that in group $\mathrm{C}(\mathrm{P}<0.05$; Fig. 7$)$, which indicated that the total antioxidant capacity of group $\mathrm{C}$ was higher compared with group D.

mRNA expression levels of $\alpha 1 a-A R, \alpha 1 b-A R$ and $\alpha 1 d-A R$ in the prostate. The mRNA expression levels of $\alpha 1 \mathrm{a}-\mathrm{AR}, \alpha \mathrm{lb}-\mathrm{AR}$, 

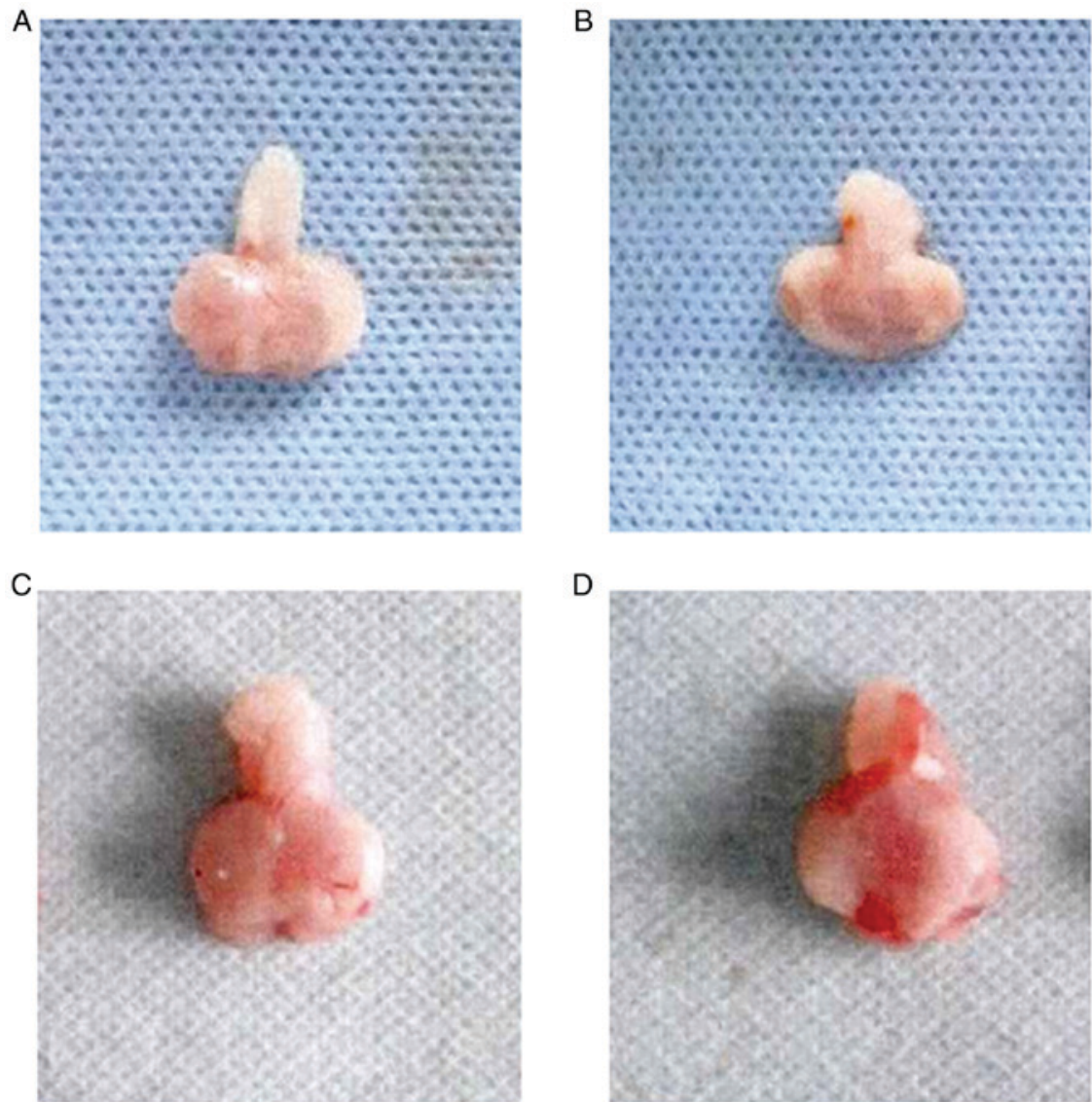

Figure 3. Morphology of the prostate gland. Differences in the morphology of (A) normal rats, (B) ethanol-drinking rats, (C) chronic non-bacterial prostatitis rats and (D) ethanol-drinking chronic non-bacterial prostatitis rats.

A

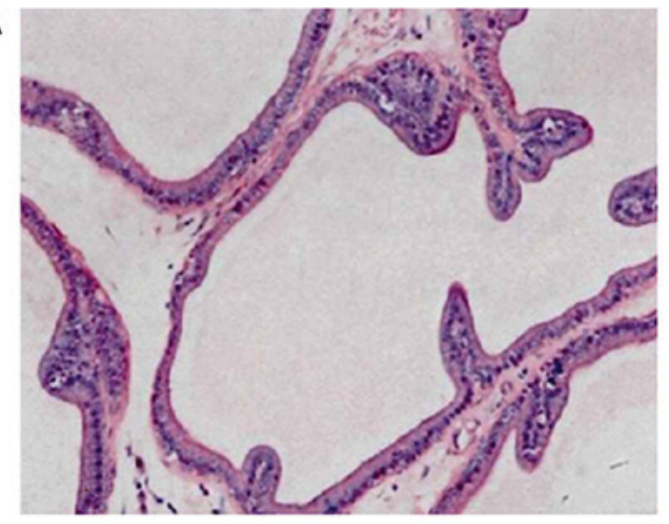

C

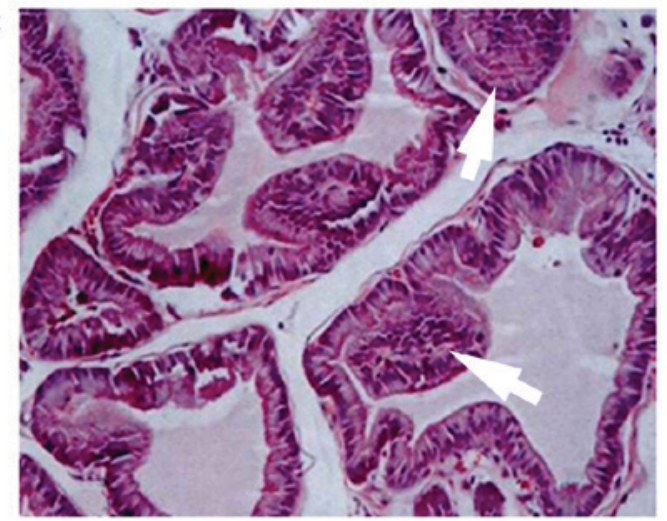

B

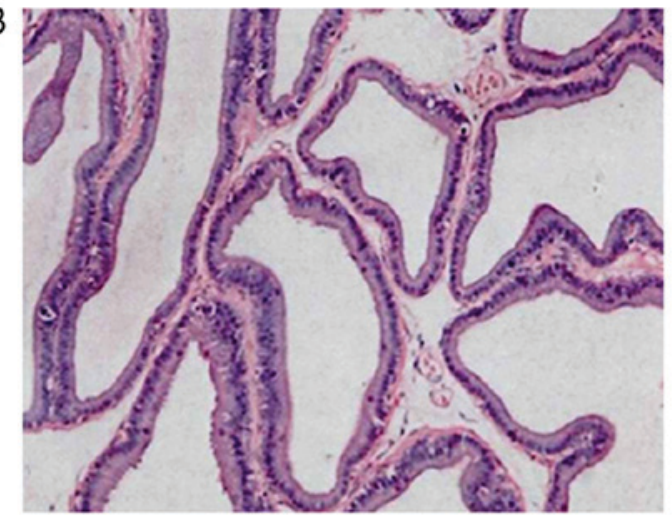

D

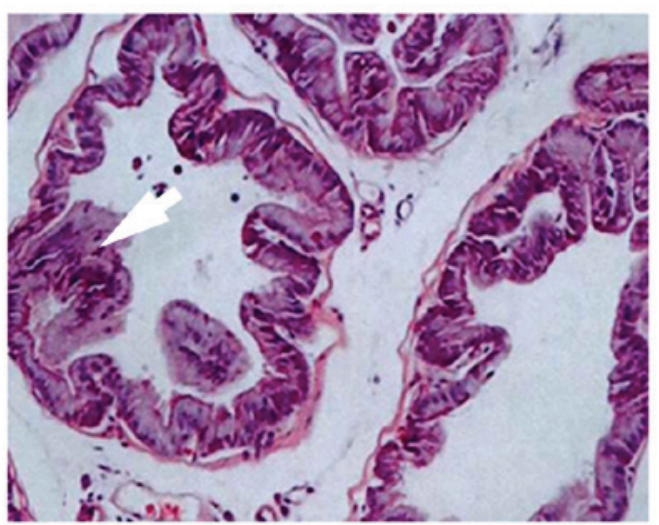

Figure 4. Morphology of the prostate gland evaluated by hematoxylin and eosin staining. Histological observation of prostate in (A) normal rats, (B) ethanol-drinking rats, (C) chronic non-bacterial prostatitis rats and (D) ethanol-drinking chronic non-bacterial prostatitis rats. Magnification, x10. 

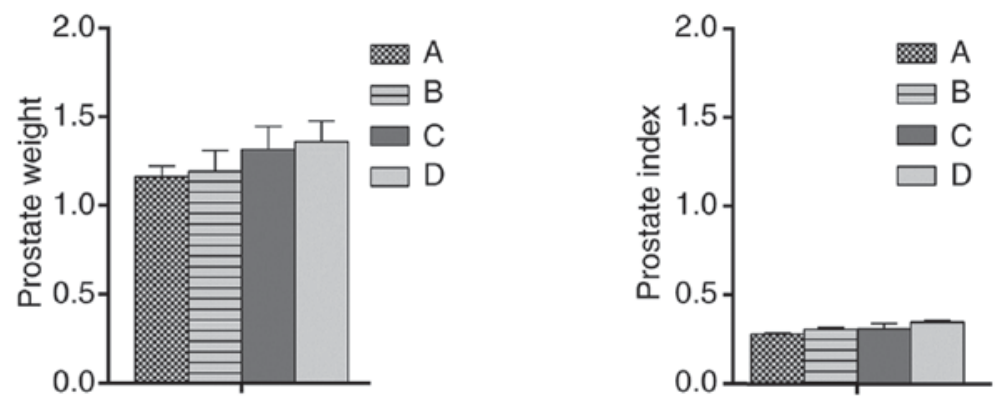

Figure 5. Prostate wet weight and index in group A (normal rats), group B (ethanol-drinking rats), group C (chronic non-bacterial prostatitis rats) and group D (ethanol-drinking chronic non-bacterial prostatitis rats). No significant differences were observed among groups.

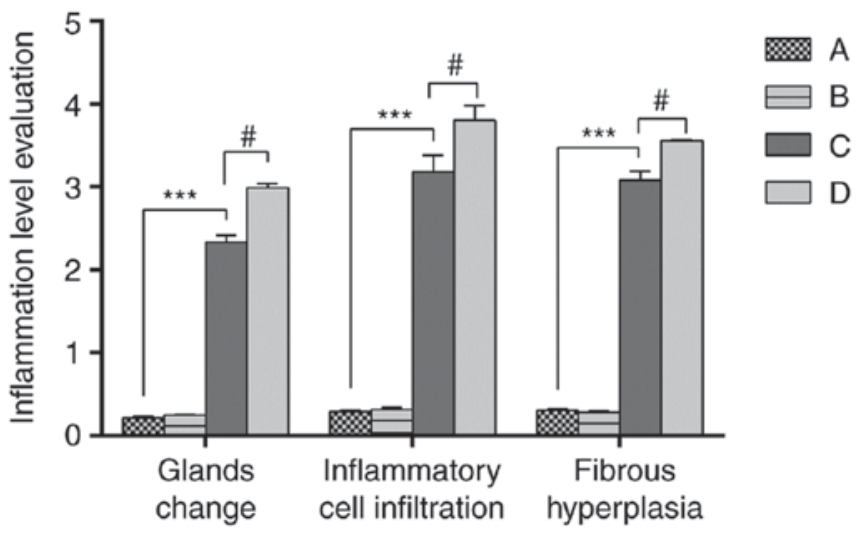

Figure 6. Evaluation of prostatic inflammation in rats of group A (normal rats), group B (ethanol-drinking rats), group $\mathrm{C}$ (chronic non-bacterial prostatitis rats) and group $\mathrm{D}$ (ethanol-drinking chronic non-bacterial prostatitis rats). ${ }^{* * *} \mathrm{P}<0.001,{ }^{\#} \mathrm{P}<0.05$. and $\alpha 1 \mathrm{~d}-\mathrm{AR}$ in the prostate of each group were detected by RT-qPCR (Fig. 8). The results demonstrated that there was no significant difference in mRNA expression of $\alpha 1 \mathrm{a}-\mathrm{AR}$, $\alpha 1 b-A R$, and $\alpha 1 d-A R$ between groups $A$ and $B$. While the expression of $\alpha 1 \mathrm{a}-\mathrm{AR}, \alpha \mathrm{lb}-\mathrm{AR}$, and $\alpha 1 \mathrm{~d}-\mathrm{AR}$ in group $\mathrm{C}$ and group D were higher compared with group A and group $\mathrm{B}$. Among the expression of $\alpha 1 \mathrm{a}-\mathrm{AR}, \alpha 1 \mathrm{~b}-\mathrm{AR}$, and $\alpha 1 \mathrm{~d}-\mathrm{AR}$, the fold change of $\alpha 1 \mathrm{a}-\mathrm{AR}$ was most significant, which indicated that the expression of $\alpha 1 \mathrm{a}-\mathrm{AR}$ may be the most important subtype among the 3 genes for inflammation.

\section{Discussion}

In the present study, SD rats were injected intraperitoneally with purified prostaglandin with double immunoadjuvant to induce non-bacterial prostatitis in rats $(16,17)$. This rat model is a good model for analyzing the effects of ethanol $(23,24)$.

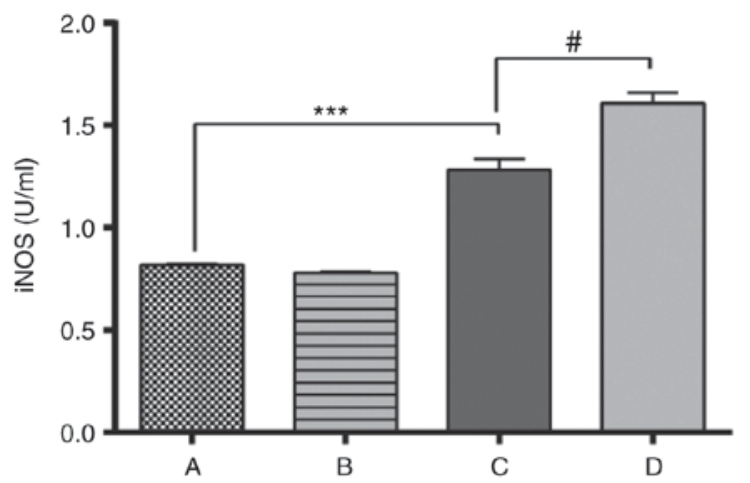

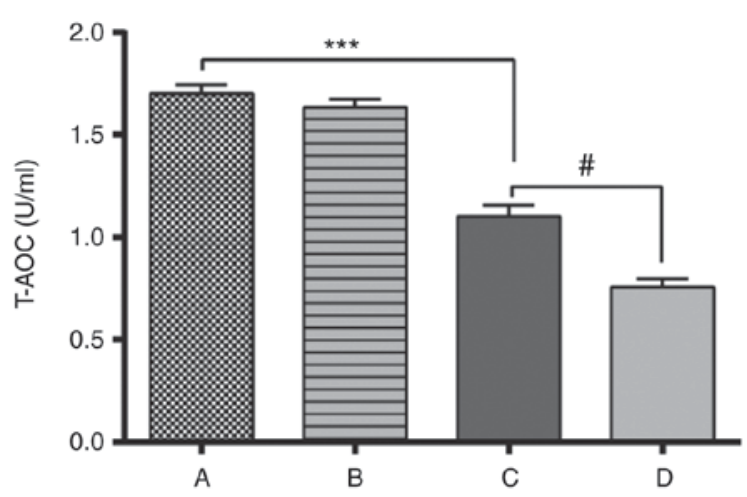

Figure 7. Expression levels of proinflammatory cytokines in the prostate of group A (normal rats), group B (ethanol-drinking rats), group C (chronic non-bacterial prostatitis rats) and group $\mathrm{D}$ (ethanol-drinking chronic non-bacterial prostatitis rats). ${ }^{* * *} \mathrm{P}<0.001,{ }^{*} \mathrm{P}<0.05$. TNF- $\alpha$, tumor necrosis factor- $\alpha$; iNOS, inducible nitric oxide synthase; T-AOC, total antioxidant capacity. 


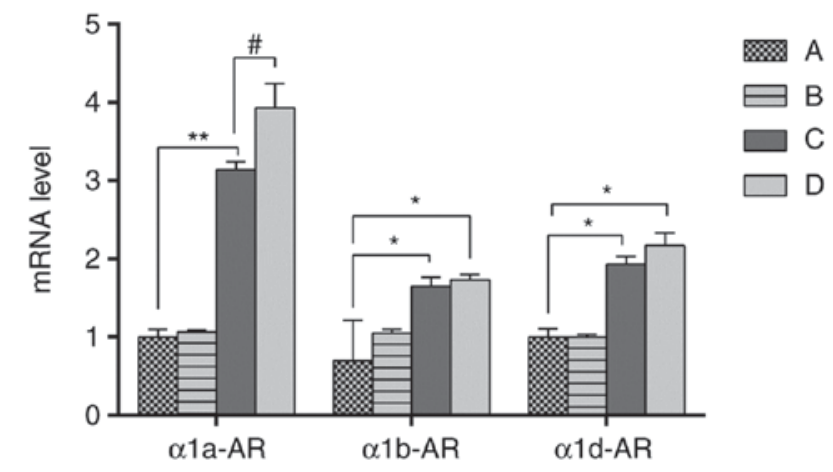

Figure 8. mRNA expression levels of $\alpha 1 \mathrm{a}-\mathrm{AR}, \alpha 1 \mathrm{~b}-\mathrm{AR}$ and $\alpha 1 \mathrm{~d}-\mathrm{AR}$ in the prostate of group A (normal rats), group B (ethanol-drinking rats), group C (chronic non-bacterial prostatitis rats) and group D (ethanol-drinking chronic non-bacterial prostatitis rats). ${ }^{*} \mathrm{P}<0.05,{ }^{* *} \mathrm{P}<0.01,{ }^{\text {"}} \mathrm{P}<0.05$. AR, adrenoreceptor.

The weight of the rats did not significantly differ among the groups, indicating that the body weight of the rats was stable during the experiment. However, internal changes were observed. The number of $\mathrm{WBC}$, the concentration of serum $\mathrm{T}$ and the concentration of $\operatorname{IgG}$ in groups $\mathrm{C}$ and $\mathrm{D}$ were increased compared with the control (group A).

Additionally, when the prostates of ethanol-exposed rats with prostatitis were removed, the prostates were damaged, and enlarged with local congestion of glands and edema. H\&E staining revealed that blood vessels were outstretched and glands were damaged in group D. These results indicated that there was inflammation in rats treated with ethanol. Significant glandular changes, severe inflammatory infiltration and hyperplasia of fibrous tissue was observed in the prostates of group D. The expression of TNF- $\alpha$, iNOS in group D rats were the highest, while the expression of T-AOC was much lower in group D group compared with group A. To further analyze inflammation levels, the mRNA expression levels of $\alpha 1 \mathrm{a}-\mathrm{AR}, \alpha 1 \mathrm{~b}-\mathrm{AR}$, and $\alpha 1 \mathrm{ld}-\mathrm{AR}$ were investigated via RT-qPCR $(25,26)$. $\alpha 1 a-A R$ expression was highest in groups $\mathrm{D}$, which indicated that $\alpha 1 \mathrm{a}-\mathrm{AR}$ may be the most important mRNA subtype in these rats.

In the present study, the association between ethanol and non-bacterial prostatitis in rats was explored. The findings indicated that ethanol may accelerate the inflammatory response in arts with prostatitis, which may provide some useful information for clinical research.

However, this study has limitations. For example, the detailed signaling pathways involved remain unclear, and potential target molecules that could be exploited to prevent non-bacterial prostatitis also need to be identified. Future studies should investigate the underlying mechanism and target molecules involved in non-bacterial prostatitis.

\section{Acknowledgements}

Not applicable.

\section{Funding}

The present study was supported by Youth Fund of Shanghai Municipal Commission of Health and Family Planning (grant no. 2011-Y132). Clinical research and cultivation fund of Renji Hospital (grant no. PYXJS16-009).

\section{Availability of data and materials}

The datasets used and/or analyzed during the current study are available from the corresponding author on reasonable request.

\section{Authors' contributions}

JY designed this study. FL and XX performed all of the experiments. LL helped to collect the data. ZW produced the figures. LC helped with the analysis and interpretation of data. All authors read and approved the final manuscript.

\section{Ethics approval and consent to participate}

The Bioethics Committee of Shanghai Jiaotong University approved all animal experiments.

\section{Patient consent for publication}

Not applicable.

\section{Competing interests}

The authors declare that they have no competing interests.

\section{References}

1. Rehm J, Samokhvalov AV and Shield KD: Global burden of alcoholic liver diseases. J Hepatol 59: 160-168, 2013.

2. Lee JH, Friso S and Choi SW: Epigenetic mechanisms underlying the link between non-alcoholic fatty liver diseases and nutrition. Nutrients 6: 3303-3325, 2014.

3. Liu YJ, Song GH and Liu GT: Investigation of the effect of traditional Chinese medicine on pain and inflammation in chronic nonbacterial prostatitis in rats. Andrologia 48: 714-722, 2016.

4. Zhao HF, Li X and Jiang XZ: Heat shock protein 9-mediated inflammation reaction in patients with chronic prostatitis with erectile dysfunction. Eur Rev Med Pharmacol Sci 20: 4185-4189, 2016.

5. Testino G: Alcoholic diseases in hepato-gastroenterology: A point of view. Hepatogastroenterology 55: 371-377, 2008.

6. Zhang DF, Zhang F, Zhang J, Zhang RM and Li R: Protection effect of trigonelline on liver of rats with non-alcoholic fatty liver diseases. Asian Pac J Trop Med 8: 651-654, 2015.

7. Anderson RU, Wise D, Sawyer T, Glowe P and Orenberg EK: 6-day intensive treatment protocol for refractory chronic prostatitis/chronic pelvic pain syndrome using myofascial release and paradoxical relaxation training. J Urol 185: 1294-1299, 2011.

8. Sahin S, Bicer M, Eren GA, Tas S, Tugcu V, Tasci AI and Cek M: Acupuncture relieves symptoms in chronic prostatitis/chronic pelvic pain syndrome: A randomized, sham-controlled trial. Prostate Cancer Prostatic Dis 18: 249-254, 2015.

9. Zibara K, Awada Z, Dib L, El-Saghir J, Al-Ghadban S, Ibrik A, El-Zein N and El-Sabban M: Anti-angiogenesis therapy and gap junction inhibition reduce MDA-MB-231 breast cancer cell invasion and metastasis in vitro and in vivo. Sci Rep 5: 12598, 2015.

10. Iwamura H, Koie T, Soma O, Matsumoto T, Imai A, Hatakeyama S, Yoneyama T, Hashimoto Y and Ohyama C: Eviprostat has an identical effect compared to pollen extract (Cernilton) in patients with chronic prostatitis/chronic pelvic pain syndrome: A randomized, prospective study. BMC Urol 15: 120, 2015.

11. Jin JX, Wang HZ, Zhai ZX, Ma BL, Li QF, Xiao N, Wang ZP and Rodriguez R: Transrectal microwave thermotherapy causing a short-time influence on sperm quality in Chinese chronic nonbacterial prostatitis patients. Asian J Androl 19: 548-553, 2016.

12. Krsmanovic A, Tripp DA, Nickel JC, Shoskes DA, Pontari M, Litwin MS and McNaughton-Collins MF: Psychosocial mechanisms of the pain and quality of life relationship for chronic prostatitis/chronic pelvic pain syndrome (CP/CPPS). Can Urol Assoc J 8: 403-408, 2014. 
13. Zijoo R, Dirweesh A, Ordonez FM and Kaji A: Spontaneous Rupture of Urinary Bladder in a Young Alcoholic Male. J Med Cases 7: 245-247, 2016.

14. Yatkin E, Bernoulli J, Lammintausta R and Santti R: Fispemifene (Z-2-\{2-(4-(4-chloro-1,2-diphenylbut-1-enyl)-phenoxy)ethoxy\}ethanol), a novel selective estrogen receptor modulator, attenuates glandular inflammation in an animal model of chronic nonbacterial prostatitis. J Pharmacol Exp Ther 327: 58-67, 2008.

15. Keetch DW, Humphrey P and Ratliff TL: Development of a mouse model for nonbacterial prostatitis. J Urol 152: 247-250, 1994.

16. Cui D, Han G, Shang Y, Mu L, Long Q and Du Y: The effect of chronic prostatitis on zinc concentration of prostatic fluid and seminal plasma: A systematic review and meta-analysis. Curr Med Res Opin 31: 1763-1769, 2015.

17. Lee G: Chronic Prostatitis: A possible cause of hematospermia. World J Mens Health 33: 103-108, 2015.

18. Magistro G, Wagenlehner FM, Grabe M, Weidner W, Stief CG and Nickel JC: Contemporary management of chronic prostatitis/chronic pelvic pain syndrome. Eur Urol 69: 286-297, 2016.

19. Lai C, Yu X, Zhuo H, Zhou N, Xie Y, He J, Peng Y, Xie X, Luo G, Zhou S, et al: Anti-tumor immune response of folate-conjugated chitosan nanoparticles containing the IP-10 gene in mice with hepatocellular carcinoma. J Biomed Nanotechnol 10: 3576-3589, 2014.

20. Zdrodowska-Stefanow B, Ostaszewska-Puchalska I, Badyda J and Galewska Z: The evaluation of markers of prostatic inflammation and function of the prostate gland in patients with chronic prostatitis. Arch Immunol Ther Exp (Warsz) 56: 277-282, 2008.
21. Delongchamps NB, de la Roza G, Chandan V, Jones R, Sunheimer R, Threatte G, Jumbelic M and Haas GP: Evaluation of prostatitis in autopsied prostates-is chronic inflammation more associated with benign prostatic hyperplasia or cancer? J Urol 179: 1736-1740, 2008.

22. Livak KJ and Schmittgen TD: Analysis of relative gene expression data using real-time quantitative PCR and the 2(-Delta Delta C(T)) method. Methods 25: 402-408, 2001

23. Kutch JJ, Yani MS, Asavasopon S, Kirages DJ, Rana M, Cosand L, Labus JS, Kilpatrick LA, Ashe-McNalley C, Farmer MA, et al: Altered resting state neuromotor connectivity in men with chronic prostatitis/chronic pelvic pain syndrome: A MAPP: Research Network Neuroimaging Study. Neuroimage Clin 8: 493-502, 2015.

24. Thakur V, Talwar M and Singh PP: Low free to total PSA ratio is not a good discriminator of chronic prostatitis and prostate cancer: An Indian experience. Indian J Cancer 51: 335-337, 2014.

25. Giannantoni A and Proietti S: Chronic prostatitis: How to give our best without apposite vagueness. BJU Int 116: 499-500, 2015.

26. Zhang Y, Zheng T, Tu X, Chen X, Wang Z, Chen S, Yang Q, Wan Z, Han D, Xiao H, et al: Erectile dysfunction in chronic prostatitis/chronic pelvic pain syndrome: Outcomes from a multi-center study and risk factor analysis in a single center. PLoS One 11: e0153054, 2016. 